\title{
On the International Education Strategies of Engineering Universities under "the Belt and Road Initiative"
}

\author{
Jiameng SUN \\ College of Foreign Languages \\ Chengdu University of Information Technology \\ Chengdu, P.R.China \\ jiameng_sun@outlook.com
}

\begin{abstract}
Among all the Chinese universities, engineering colleges are characterized with strong, distinct and industryoriented disciplines. However, the classification and transformation of different colleges leads to apparent gap between engineering universities and their comprehensive counterparts, especially in the area of international education. Against the backdrop of "the Belt and Road Initiative", a blueprint for the development of opening-up to the outside world has been painted out. This paper analyses the current situation and finds several strategies for engineering universities and colleges in the development international education, including strengthens international exchanges and cooperation, adopting the CDIO engineering education mode, establishing schoolenterprise collaboration and innovation platforms, so as to explore more opportunities for the international education reform of engineering universities.
\end{abstract}

Keywords - the belt and road initiative; International education engineering universities and colleges

\section{INTRODUCTION}

In 2013, during a visit to Southeast Asian countries, President of China, Xi Jinping proposed a major initiative to jointly build the "Silk Road Economic Belt" and the "21st Century Maritime Silk Road" ("Belt and Road"), with a highlight in adhering to humanistic exchanges and economic cooperation with countries along the line, including areas such as education, tourism and art. Therefore, a number of largescale cross-border engineering projects are born and in full swing. However, a shortage of engineering talents, who not only master industrial knowledge and kill but also know the international code of conduct, hinders the rapid development of overseas business. This phenomenon reflects the gap between the international education and talents training of engineering universities in China, which is urgent to be optimized and upgraded $^{[1]}$. In this context, the reform of international education in engineering universities not only plays an important role in promoting the internationalization of China's higher education, but also provides a strong impetus to enhance its scientific and technological strength. At the same time, valuable opportunities are provided for achieving goals in cultural exchange and cooperation against the backdrop of Belt

The Belt and Road Initiative Annual Project of Chengdu University of Information Technology, NO. CRFYY1711 and Road Initiative ${ }^{[2]}$.

II. SWOT ANALYSIS OF INTERNATIONAL EDUCATION OF ENGINEERING COLLEGES UNDER "BeLt AND ROAD INITIATIVE"

SWOT analysis is an internationally recognized analysis tool that can effectively sort out conditional factors relating the target, with further clarification on the Strength, Weakness, Opportunity and Threat of the research object. Based on the SWOT model, this paper explores the current situation of international education reform in engineering universities and colleges.

\section{A. Strength}

First, since the reform and opening up of China 40 years ago, the economy and society have achieved certain goals in the development of higher engineering education. For example, the scale of Chinese higher engineering education is currently the largest in the world, and tens of millions of technical talents have been trained to meet the development of the society. Secondly, through years of accumulation, many colleges and universities have undergone transformation and formed their dominant disciplines with advantageous competitiveness and good social reputation. In addition, engineering colleges are usually closely connected to related industries. So that experts and scholars in research teams can capture the latest industrial trends in time, which is helpful to establish a stable cooperation model of "production, study and research", and to train industry-oriented talents in the engineering field.

\section{B. Weakness}

It is undeniable that the status quo of international education in engineering universities can hardly adapt to the requirements of the "Belt and Road Initiative", which is mainly reflected in the following aspects.

First, the implementation of the concept of international education was adopted quite late in engineering universities thus resources are relatively scarce. Although some engineering universities seized the opportunity of finding foreign partners with similar disciplinary advantages, and began to run Chinese-foreign cooperation projects, the combination of theory and practice of international education 
in most schools still falls short, and the internationally integrated teaching model and modern infrastructures are not completely in place. Second, there is a deficiency in the development of international staff. The internationalization of the teaching staff largely decides the possibility of the training of internationalized students ${ }^{1}$. While the truth is that only a small portion of teachers in traditional engineering colleges boast an overseas experience, neither for work nor study. Even few of the teachers can teach a course bilingually or totally in English. Therefore, the process of "engineering demonstration" seems hard to manage with international standards. The third is that students' international awareness and innovative practice need to be improved. Largely influenced by the traditional education system with emphasis on theory over practice, engineering students tend to learn skills and conduct innovation practice separately from the reality. In addition, limited by their relatively weak English language proficiency, they usually find it's hard to make in-depth discussions with foreign teachers and students in English, especially on professional academic topics.

\section{Opportunity}

In the process of economic globalization, the flow of resources and talents in various fields around the world has been flowing in and out more frequent. International resources in education are particularly obvious. In order to better allocate educational resources and improve the competitiveness and academic influence, and to make full use of the previous achievements of China's higher engineering education, the "Excellent Engineer Education and Training Program" has been specially proposed by the National Medium-and-long Term Education Reform and Development Program (20102020), among which about 210 colleges and universities were included. The state has given great support to the plan from the policy, resources and platform. It aims to train a large number of engineering and technical personnel with innovative capability and adaptability to the needs of economic and social development. Finally, provide a strong talent-bank for the development of higher engineering education, so as to achieve the goal of establishing an innovative-oriented country by taking the road of new industrialization.

\section{Threat}

Opportunities are always in the wake of challenges. At present, the international education of engineering universities in China faces both internal and external challenges. As an important part of the "Belt and Road Initiative", communication in humanities plays a fundamental role, like a bridge or an ice-breaker ${ }^{[3]}$. Although the internationalization of personnel training in engineering universities has made some progress after the reform and opening up, when compared with other similar colleges and universities, it is still at disadvantage in various factors such as the quality of teachers and students, level of academic platforms, and opportunities for international

${ }^{1}$ According to statistics that $81 \%$ of the academicians in Chinese Academy of Sciences, $54 \%$ of the academicians of the Chinese Academy of Engineering, and 94\% of the Yangtze River scholars all have an international background. Half of the overseas high-level talents that introduced by China's “Thousand Talents Program” are employed in top universities. exchange and cooperation. For example, compared with other comprehensive colleges and universities in China, engineering colleges generally have difficulties in having unique characteristics in both teaching content and models, and there's always a comparatively lower conversion rate from academic research into innovation and practical results in entrepreneurship. Looking from the outside, overseas educational resources enjoy good sales and are highly attractive to the talented teachers and student, so that it is of great importance for domestic engineering colleges and universities to find out their unique superiorities and make preparation in advance to attract outstanding students and teaching staff both at home and abroad.

\section{CONSTRUCTION OF CONCEPTS}

At the Innovative Entrepreneurship and Higher Engineering Education Development Seminar hosted by the China Association of Higher Education on December $21^{\text {st }} 2017$, academician $\mathrm{Wu}$ Zhaohui, Vice President of the China Association of Higher Education and President of Zhejiang University, pointed out that currently China is faced with the target of growing from large into strong in the field of engineering education. In that case, with a promising future and abundant opportunities, international engineers are also confronted with numerous challenges.

Nowadays, internationalization has become the trend of development in most top universities and colleges around the globe. Yale University stated in its strategic framework that internationalization is their response to the opportunities and challenges in a world full of changes, and New York University opened a branch campus in Shanghai, all of which reflected the increasing internationalization of education. In order to train qualified international talents, the United States has also implemented several programs, including the "Preparing Future Faculty Program" (PFF), the "Integrative Graduate Education and Research Traineeship”(IGERT), the "Re-planning $\mathrm{PhD}$ ", and the "Center for the Integration of Research, Teaching and Learning”(CIRTL), Carnegie Innovation Program for Doctorates(CID), etc. The EU also implements the EuRopean Community Action Scheme for the Mobility of University Students (ERASMUS) Program and the EU Foreign Languages and Knowledge Promotion Program (LINGUA) $^{[4]}$.

\section{EXPLORATION ON STRATEGIES}

Over the past 4 decades, the number of overseas students studying abroad has reached 5.194 million. According to statistics, in 2017, the number of students studying abroad exceeded 600,000 for the first time, reaching 608,400 , with an increase of $11.74 \%$ over the same period of last year ${ }^{[5]}$. It makes China the world's largest exporter of students study abroad and Asia's largest destination for foreign students. Various university alliances, such as the Universities Alliance of the New Silk Road (UANSR),the Belt and Road University Strategic Alliance, and the Universities Alliance of the New Maritime Silk Road, etc., are led by Chinese universities and gradually strengthened their cooperation with relevant nations and regions in fields like inter-school exchanges, personnel training and research 
cooperation. It is undoubted that China's education has achieved some results and gradually established good and stable international cooperation with some higher educational institutions in developed countries. However, there are still considerable room for improvement in scheme and layout of the joint educational programs between Chinese and foreign universities, which limits the all-round development of higher engineering education to a certain extent ${ }^{[6]}$.

As is mentioned above, engineering colleges and universities have distinctive characteristics and advantages in international cooperation, as well as weaknesses. Based on statistics and experience, the successful international cooperation model for engineering colleges should mainly focus on the professions and disciplines with strong applicability and high conversion rate to industry. Engineering colleges and universities can explore international education reform from the following four aspects: communication mechanism, education mode, school-enterprise cooperation, and innovation and entrepreneurship.

\section{A. strengthen international exchange and cooperation}

Encourage students and teachers to go abroad for a purpose of learning and communication. Different cultures and countries are quite different in development modes with their rich and varied history and culture. As engineering students, it is far from enough to know the world, which is full of infinite possibilities, only from the perspective of natural science. Therefore, in order to have students experience the essential differences between Chinese and foreign cultures and the teaching and learning patterns, it is necessary to encourage them to go abroad for either long-term or short-term study. In the meantime, it provides opportunities for them to be engaged in foreign-language-speaking immersive environment both for learning and living.

Teachers, on the other hand, as the practitioners of international education, need to understand foreign customs and, more importantly, to master the advanced technologies and skills in engineering experiments, researches and projects. So it is obvious that if engineering schools want to truly achieve internationalization and do a good job in Sino-foreign cooperative education, the internationalization of the teaching staff is top priority. If teachers do not have an international vision or experience, they will not be able to look at the world critically and open-mindedly, let alone the students. Therefore, teachers should be fully aware that they are not only the professional trainers, but also educators with globalized consciousness, who can show students a way to the world.

\section{B. Adopt CDIO Engineering Model}

$\mathrm{CDIO}$ is an engineering education reform program initiated by four engineering universities, namely Massachusetts Institute of Technology, Chalmers University of Technology, KTH Royal Institute of Technology and Linkoping University. They put forward the concept of CDIO engineering education and established an international organization. Till April 2017, 104 universities around the world have volunteered to join the CDIO engineering education alliance. As the world's most advanced engineering education system, CDIO combines its four integrated elements (Conceive-Design-Implement-Operate) to the teaching of students in accordance with their aptitude, practical skills and comprehensive quality. According to the engineering professional evaluation index of the American Accreditation Board for Engineering and Technology (ABET) [7][8], and based on characteristics of China's engineering industry, the application of CDIO in engineering universities in China is mainly embodied in engineering design. It focuses on the pursuit of professional qualities for potential engineers, which finds its demonstration in advanced engineering and technical capabilities with problem-oriented theoretical knowledge and practical skills ${ }^{\left[{ }^{[}\right]}$. Therefore, the training of international engineers should be based on the "One Belt One Road Initiative", focusing on the both the improvement of engineering-based superiority and language ability.

(TABLE. I)What's more, the CDIO Initiative in Engineering Education systematically put forward 12 standards in a long-term program that contains operation, implementation, inspection and evaluation, which are organically integrated together. The introduction of CDIO engineering education mode into China shows that China's higher education hopes to train engineers who are in line with international standards. Therefore, colleges and universities have carried out a series of CDIO localization exploration activities according to their own characteristics and professional needs, including aspects of personnel training, teaching curriculum system, team building and scientific research, etc. One thing that should be well recognized is that the international education reform of engineering universities and colleges should not be merely a technical trial, but should break through the constraints of the cliché. It is necessary not only to pay attention to students' scientific and technical knowledge, but also to cultivate their lifelong learning awareness, teamwork spirits and communication skills, so as to enable them to work and live in the society after graduation. CDIO Initiative is the latest achievement in innovative and practical education, which can greatly improve students' abilities in design, innovation and communication.

TABLE I.

CDIO INITIATIVE IN ENGINEERING EDUCATION

\begin{tabular}{|c|c|c|}
\hline \multirow{2}{*}{$\begin{array}{c}\text { CDIO } \\
\text { Syllabus }\end{array}$} & \multicolumn{2}{|c|}{$\mathbf{1 2}$ Standards in Teaching } \\
\hline \multirow{4}{*}{$\begin{array}{c}\text { Disciplinary } \\
\text { Knowledge }\end{array}$} & \multirow{2}{*}{ Curriculum } & Standard 1. Definition \\
\cline { 3 - 3 } & & Standard 2. Learning Outcome \\
\cline { 3 - 3 } & & Standard 3.Integratedd Curriculum \\
\cline { 3 - 3 } & & Standard 4. Introduction \\
\hline \multirow{2}{*}{ Personal Skills } & Workspace & Standard 5. Implement Experience \\
\hline Interpersonal & Teaching & Standard 7. Real-world Learning \\
\cline { 3 - 3 } Skills & Methods & Standard 8. Active Learning \\
\hline \multirow{2}{*}{ CDIO Skills } & Faculty & Standard 9. Staff CDIO Skills \\
\cline { 3 - 3 } & Competence & Standard 10. Staff Teaching Skills \\
\cline { 3 - 3 } & & Standard 11. CDIO Skills \\
& Assessment & Assesment \\
\cline { 3 - 3 } & & Standard 12. CDIO Program \\
& & Evaluation \\
\hline
\end{tabular}

\section{Enhance School-enterprise Cooperation}

The engineering universities and colleges are highly characterized with industrial-orientation. To train outstanding talents for the engineering industry, it is essential to work 
closely with relevant enterprises, associations and institutions. At present, many Chinese companies that set up branches or offices overseas have found a common problem that most Chinese engineers are more or less confined by their international experience, thus are more likely to be confronted with challenges in integrating into local culture and society. To solve this problem, it is necessary to fully respond to the propose to cooperate with countries along the "Belt and Road Initiative", and to set up-to-date training objectives for sustainable development, which may help the engineer students and technicians be more adaptable to different enterprises, societies and cultures at large.

On the other hand, while conducting scientific research, colleges and universities should continue to accumulate technical resources, transform scientific and technological achievements, and explore international expansion through overseas cooperation with foreign enterprises ${ }^{[10]}$. Therefore, Chinese-foreign cooperative education in engineering colleges must be closely linked with the local enterprises by sharing complementary resources and for win-win result.

\section{Encourage Innovation and Entereprenuership}

Innovation is the soul and foundation of a booming industry, and at the same time, it's also the core competitiveness of a college or a university. For one thing, innovation and entrepreneurship are not only conducive to deepening school-enterprise cooperation, but also beneficial to the integration of educational production in the field of engineering. For another, it provides incentives and demonstrations for the reform of engineering education in operation, for example, the restructuring of disciplines, and the innovation of talent training models. Due to different characteristics of the industry, engineering colleges should conform to the development trend and stimulate the enthusiasm of teachers and students for the purpose of innovation and entrepreneurship. Most overseas engineering colleges pay great attention to students' innovative learning ability. In the process of Sino-foreign educational cooperation, the "Belt and Road" strategy is of high value in building high-tech talent platforms in universities, among which building innovation labs and workshops and creating innovation start-ups will do the trick. For example, in combination with the school's characteristics, the innovation-driven strategy could be conducive in creating innovative and entrepreneurial brands of their own dominant disciplines, and to form a loop on this condition, like an innovative ecosystem within a company. Furthermore, to encourage teachers to transform scientific research results into innovative and entrepreneurial achievements accordingly, this can have students participate in innovation and entrepreneurship projects. Generally speaking, integration of theoretical knowledge and practical skills has further improved the innovative training mechanism and management system.

\section{SUMMARY}

Through the analysis of the international talent training mode of engineering colleges under the background of "Belt and Road", it is not difficult to conclude that it is imperative to strengthen the breadth and depth of international exchanges and cooperation. It is imperative to improve the international vision and intercultural communication ability of teachers and students. It is urgent to cultivate the reform of compound international engineering talents. It is necessary to adopt a multi-pronged approach in terms of policy, model and strategy. Based on the rich resources and engineering disciplines of colleges and universities, it will increase cooperation with enterprises in innovation and entrepreneurship. The concept of "talent first" is implemented in the "One Belt, One Road" strategy.

\section{REFERENCES}

[1] Li Luping, Cao Jun, Zhang Yonghua, “Analysis on problems, causes and countermeasures of education in former higher engineering," J. China University Teaching, 2010, pp.24-26. (In Chinese)

[2] Bai Lu. "Discussion on strategies of internationalization of higher education under the Belt and Road Initiative,” J. New West, 2015, pp.121. (In Chinese)

[3] Mok, K. H, "Questing for internationalization of universities in Asia: Critical reflections." J. Journal of Studies in International Education, 2007,11(313):433-454.

[4] Xiong Ling, Li Zhong, "Reports on demand for engineering talents in the new century,” J. Modern Education Management, 2010,pp.4. (In Chinese)

[5] http://www.moe.gov.cn/jyb_xwfb/gzdt_gzdt/s5987/201803/t20180329_ 331771.html

[6] Li Yu, "Mechanism construction of effective communication on culture and education," N. vol. 2, Beijing, Chinese Social Sciences Weekly, March 2016

[7] http://web.MIT.edu/annualreports/pres02/Dean,School of Engineering.

[8] NAE. "Educating the engineer of 2020: adapting engineering education to the new century," Z. Washington DC: The National Academies Press, 2005.

[9] http://www.cdio.org/

[10] Zhao Lixian, "What are the key features of international talents," J. International Talent, Vol.7, 2013, pp.55. (In Chinese) 